\title{
Analisis Kualitas Layanan Rumah Susun Sederhana Sewa (Rusunawa) Semeru dengan Menggunakan Metode Importance Performance Analysis (IPA) ${ }^{1}$ (Sudi Kasus : Rumah Susun Sederhana Sewa (Rusunawa) Semeru di Desa Triwungkidul, Kecamatan Kademangan, Kota Probolinggo)
}

\section{Analysis of Semeru Simple Rental Flats (Rusunawa) Service Quality Analysis Using the Importance Performance Analysis (IPA) Method}

Yovita Inggar Mawardia, Ratri Wulandari ${ }^{\mathrm{a}}$, Gusti Kinanti Wahyu Istiqomah ${ }^{\mathrm{a}}$, Rheynaldi Lintang Susila ${ }^{\mathrm{a}}$, Aulia Ilecsi Hendriavi ${ }^{\mathrm{a}}$

${ }^{a}$ Program Studi S1 Perencanaan Wilayah dan Kota, Jurusan Teknik Sipil, Fakultas Teknik, Universitas Jember, Jl. Kalimantan 37 Jember

\begin{abstract}
ABSTRAK
Perumahan merupakan kebutuhan dasar yang sangat penting bagi kelangsungan hidup masyarakat. Perumahan dan permukiman yang bagus dapat meningkatkan kualitas sumber daya manusia dan meningkatkan kualitas hidup dan pemerataan kesejahteraan rakyat. pengadaan rumah susun adalah salah satu alternatif untuk menangani permasalahan kebutuhan perumahan dan permukiman yang ada di kota yang cenderung memiliki peningkatan penduduk yang cukup pesat. Rumah susun merupakan solusi alternatif yang cukup efektif karena pembangunan rumah susun dapat menghemat penggunaan tanah, membuat peremajaan kota bagi daerah yang kumuh, dan memberikan bantuan terhadap Masyarakat Berpenghasilan Rendah. Kebutuhan hunia untuk masyarakat yang berpenghasilan rendah (MBR) semakin terua meningkat, untuk mengatasi permasalahan hunian bagi masyarakat berpenghasilan rendah, salah satu kebijakan dan strategi Pemerintah Kota Probolinggo dalam membantu masyarakat untuk menyediakan tempat tinggal bagi keluarga kurang mampu adalah dengan adanya penyediaan Rumah Susun (Rusunawa) Semeru. Dengan adanya Rusunawa diharapkan mampu memberikan hunian yang nyaman dan layak untuk bisa meningkatkan kualitas hidup penghuni Rusunawa. Namun, fungsi dari rusunawa tersebut kenyataannya belum tercapai karena hanya melihat bentuk fisik dari rusunawa tanpa melihat persepsi dan kebutuhan sarana prasarana dari penghuni. Metode yang digunakan adalah deskriptif kualitatif dan analisis Importance Performance Analysis (IPA). Hasil penelitian menjelaskan bahwa terdapat variabel - variabel sarana prasarana yang belum optimal dikarenakan tidak terawat dan pengelolaannya masih belum optimal, berdasarkan analisis tingkat kepuasan masyarakat penghuni rusunawa dihasilkan strategi untuk meningkatkan kualitas layanan. Dengan strategi tersebut diharapakan bisa terealisasi dan dapat menunjang keberlangsungan kehidupan yang lebih baik lagi untuk penghuni Rusunawa Semeru.
\end{abstract}

Kata kunci: Rusunawa, Kualitas Pelayana, dan Importance Performance Analysis (IPA)

\begin{abstract}
Housing is a basic need that is very important for the survival of the community. Good housing and settlements can improve the quality of human resources and improve the quality of life and equitable distribution of people's welfare. the provision of flats is one alternative to address the problem of housing and settlement needs in cities that tend to have a fairly rapid increase in population. Flats are an alternative
\end{abstract}

1 Info Artikel: Received: 30 Desember 2019, Accepted: 14 Januari 2020 
solution that is quite effective because the construction of flats can save land use, make urban rejuvenation for slums, and provide assistance to Low-Income Communities. The need for housing for low-income people $(M B R)$ is increasing, to overcome housing problems for low-income people, one of the policies and strategies of the Probolinggo City Government in assisting the community to provide shelter for underprivileged families is the provision of Flats (Rusunawa) ) Semeru. With the existence of Rusunawa, it is expected to be able to provide comfortable and decent housing to improve the quality of life of Rusunawa residents. However, the function of the flat is not yet achieved because it only looks at the physical form of the flat without looking at the perceptions and needs of infrastructure facilities from the residents. The method used is descriptive qualitative and Importance Performance Analysis (IPA) analysis. The results of the study explained that there are infrastructure variables that are not optimal because they are not maintained and their management is still not optimal, based on an analysis of the level of satisfaction of the residents of Rusunawa residents, a strategy to improve service quality is produced. It is hoped that this strategy can be realized and can support a better life for Rusunawa Semeru residents.

Keywords: Housing, Service Quality and Importance Performance Analysis (IPA)

\section{PENDAHULUAN}

Perumahan merupakan kebutuhan yang sangat penting bagi masyarakat. Produkproduk yang ditawarkan oleh pengembang kepada konsumennya tentunya harus berorientasi kepada kebutuhan konsumen. Kepuasan konsumen atas pembelian rumah yang ditawarkan merupakan impian dari setiap pengembang. Masyarakat yang semakin maju membutuhkan keamanan, kenyamanan dalam lingkungan perumahaan atau huniannya (Putri, 2019). Perkembangan suatu kota membawa berbagai macam dampak bagi pola kehidupan masyarakat kota itu sendiri, salah satunya dampak akan tingginya arus urbanisasi. Dampak dari tingginya arus urbanisasi selalu berkaitan dengan permukiman kota (Pandelaki, 2015). Pembangunan rumah susun merupakan salah satu alternatif untuk menangani permasalahan kebutuhan perumahan dan permukiman yang ada di kota yang cenderung memiliki peningkatan penduduk yang cukup pesat. Sistem pengelolaan yang baik perlu diadakan untuk menjaga pemanfaatan bangunan dan penghuni rusunawa yang harmonis. Apabila hal tersebut tidak dijaga maka akan terjadi penurunan kualitas bangunan dan penghuninya. Apabila kondisinya kurang terawat, rusak, dan sarana prasana juga kurang berfungsi dengan baik maka secara kualitas dapat dinyatakan mengalami penurunan. Penurunan kualitas secara terus menerus disebut dengan proses pengkumuhan atau berubah menjadi kumuh.

Tujuan penyediaan rumah susun adalah untuk memenuhi kebutuhan rumah yang layak terutama bagi MBR dengan kepastian hukum dalam pemanfaatannya serta untuk meningkatkan daya guna dan hasil guna tanah perkotaan dengan memperhatikan kelestarian sumber daya alam dan menciptakan lingkungan permukiman yang lengkap, serasi, dan seimbang. Sehingga rumah dapat dijadikan sarana pembinaan keluarga dalam pembentukan kepribadian, watak serta pendidikan yang baik sesuai dengan harkat dan martabat manusia (UU Nomor 20 Tahun 2011 tentang Rumah Susun). Masyarakat berpenghasilan rendah (MBR) adalah masyarakat yang mempunyai keterbatasan daya beli sehingga perlu mendapat dukungan pemerintah untuk memperoleh rumah (Pasal 1 Angka 24 UU Nomor 1 Tahun 2011 tentang Perumahan dan Kawasan Permukiman). Pihak pemerintah harus membantu menyediakan hunian yang layak bagi MBR. Program penyediaan hunian yang layak dapat berupa landed houses maupun vertical houses. Namun, mengingat luas lahan yang semakin terbatas dan keterbatasan kemampuan MBR untuk menjangkau landed houses, maka vertical houses dinilai sebagai program yang 
tepat. Salah satu bentuk Vertical Houses yang dinilai tepat untuk membantu MBR dalam menjangkau hunian yang layak adalah rusunawa (Irfiyanti, 2014).

Kota Probolinggo adalah salah satu kota di Provinsi Jawa Timur yang memiliki tingkat kepadatan penduduk sebesar 4.155,31 orang per $\mathrm{km}^{2}$. Dengan kepadatan penduduk yang signifikan tersebut maka dibutuhkan peningkatan kesejahteraan masyarakat terutama masyarakat yang berpengasilan rendah (MBR). Salah satu kebijakan Pemerintah Kota Probolinggo untuk meningkatkan kesejahteraan bagi masyarakat yang berpengasilan rendah (MBR) yaitu dengan penyediaan Rumah Susun agar mendapatkan tempat tinggal yang layak huni, aman, nyaman, sehat dan murah. Faktor keamanan dan kenyamanan penting dengan penempatan ruang terbuka publik yang berpotensi membangkitkan aktivitas interaksi sosial harus dirancang di area pusat perumahan yang dikelilingi oleh jalan, sehingga komunitas perumahan yang memiliki aktivitas di ruang terbuka publik dapat mengawasi kondisi perumahan (Koesoemawati, 2019). Peranan ibu rumah tangga dan anak-anak mempengaruhi intensitas interaksi sosial pada ruang publik dikarenakan faktor ekonomi dan keterbatasan lahan (Koesoemawati, 2017).

Dalam hal ini peneliti mengambil studi kasus di Rusunawa Semeru yang terletak di Triwung Kidul, Kecamatan Kademangan, Kota Probolinggo, Jawa Timur. Rusunawa Semeru memiliki luas $5.589 \mathrm{~m}^{2}$ dengan jumlah 5 lantai serta jumlah unit 94 unit/ $40 \mathrm{~m}^{2}$ dan tiga diantaranya diperuntukan untuk penyandang disabilitas yang berada di Jl. Semeru, Keluarahan Triwung Kidul, Kecamatan Kademangan. Pemilihan lokasi tersebut diarahkan pada lokasi atau kawasan yang memiliki potensi untuk dapat dikembangkan dalam penanggulangan kawasan kumuh perkotaan dan ditujukan pada masyarakat berpenghasilan rendah yang berada atau tinggal di Kota Probolinggo. Mayoritas masyarakat di Kecamatan Kademangan merupakan masyarakat berpenghasilan rendah dengan pekerjaaan sebagai petani, swasta dan nelayan. Karena kondisi geografis berupa pesisir dan terdapat banyak perumahan kumuh yang tidak layak huni, akhirnya pemerintah membangun Rusunawa agar penyediaan tempat tinggal untuk masyarakat berpenghasilan rendah (MBR) dapat terpenuhi dengan baik dan dapat meningkatkan kesejahteraan masyarakat Kota Probolinggo.

Pembangunan rusunawa di Indonesia memiliki beragam permasalahan seperti pada tahun 2007 bahwa masalah kualitas bangunan rusunawa menjadi permasalahan utama. Hal tersebut dikarenakan pembangunan rusunawa tidak memperhatikan kualitas dan perawatan bangunan dengan baik serta keberlanjutan pemanfaatan bangunan tersebut yang mengakibatkan penurunan kualitas bangunan. Masalah lain juga berupa pemanfaatan ruang yang tidak sesuai dengan fungsi ketentuan pemakaian, kondisi prasarana dan sarana umum (PSU) yang kurang memenuhi kebutuhan standart minimal dan sering terjadi kerusakan, fisik bangunan yang kurang terawat, dan kekumuhan karena pemanfaatan ruang yang tidak sesuai fungsi (Hidayati, 2017).

Maka dari itu, untuk mengatasi permasalahan tersebut perlu dilakukan evaluasi pasca huni terhadap kualitas Rusunawa Semeru sebagai penyediaan hunian bagi masyarakat berpenghasilan rendah (MBR) sehingga dapat mengetahui kualitas yang terdapat di Rusunawa Semeru, evaluasi ini digunakan untuk mengkaji peningkatan nilai keberhasilan suatu bangunan dalam memberikan rasa kepuasan yang dapat memberikan dukungan kepada penghuni dalam memenuhi kebutuhan dari penghuni Rusunawa Semeru Desa Triwung Kidul Kecamatan Kademangan Kota Probolinggo. 


\section{TUJUAN PENELITIAN}

1. Mengetahui kualitas layanan di Rusunawa Semeru.

2. Mengidentifikasi persepsi penghuni Rusunawa terhadap kualitas layanan Rusunawa Semeru.

3. Merumuskan strategi penanganan sesuai dengan keinginan penghuni Rusunawa.

\section{METODE PENELITIAN}

Penelitian ini dilaksanakan di lokasi Rusunawa Semeru Probolinggo dengan menggunakan metode deskriptif kuantitatif dan kualitatif yang dilaksanakan melalui pengamatan survey lokasi dan analisis data. Sebelum pelaksanaan penelitian ini maka diperlukan adanya desain penelitian untuk memudahkan dalam mencapai tujuan dan hasil penelitian secara maksimal dan relevan. Desain penelitian yang digunakan adalah seperti pada table berikut ini.

Tabel 1. Desain Penelitian

\begin{tabular}{|c|c|c|c|c|c|}
\hline No. & Tahapan Penelitian & $\begin{array}{l}\text { Data yang } \\
\text { dibutuhkan }\end{array}$ & $\begin{array}{c}\text { Teknik Pengumpulan } \\
\text { Data }\end{array}$ & $\begin{array}{l}\text { Metode } \\
\text { Analisis }\end{array}$ & Hasil \\
\hline 1 & $\begin{array}{l}\text { Menentukan atribut } \\
\text { kepuasan penghuni } \\
\text { rusunawa }\end{array}$ & $\begin{array}{l}\text { Pelayanan } \\
\text { pengelolaan } \\
\text { rusunawa }\end{array}$ & $\begin{array}{ll}\text { - } & \text { Peraturan yang } \\
\text { berlaku terkait } \\
\text { pengelolaan } \\
\text { rusunawa } \\
\text { - } \quad \text { Kajian Literatur }\end{array}$ & Deskriptif & $\begin{array}{l}\text { Atribut } \\
\text { kepuasan } \\
\text { penghuni } \\
\text { (sementara) }\end{array}$ \\
\hline 2 & Survey Pendahuluan & $\begin{array}{l}\text { Hasil } \\
\text { penentuan } \\
\text { atribut } \\
\text { sementara }\end{array}$ & $\begin{array}{l}\text { Wawancara } \\
\text { Survey }\end{array}$ & $\begin{array}{l}\text { Uji Validitas dan } \\
\text { Reliabilitas }\end{array}$ & $\begin{array}{l}\text { Atribut } \\
\text { kepuasan } \\
\text { penghuni }\end{array}$ \\
\hline 3 & $\begin{array}{l}\text { Pengukuran } \\
\text { kepuasan penghuni } \\
\text { rusunawa }\end{array}$ & $\begin{array}{l}\text { Hasil } \\
\text { penentuan } \\
\text { atribut akhir }\end{array}$ & Kuesioner & IPA & $\begin{array}{l}\text { Kepuasan } \\
\text { penghuni } \\
\text { rusunwa }\end{array}$ \\
\hline
\end{tabular}




\section{- $\quad$ Pengumpulan Data}

Kebutuhan data dalam penelitian ini meliputi data primer dan data sekunder. Data sekunder berupa siteplan, dokumen kontrak, gambar situasi dan peta citra lokasi rusunawa. Data primer berupa pengisian kuisioner kepada responden penghuni Rusunawa. Metode yang digunakan dalam pengambilan sampel responden adalah sampel random sampling. Populasi penelitian ini adalah warga penghuni yang ada di Rusunawa Semeru Probolinggo. Dengan tingkat ketelitian +- $20 \%$ dari jumlah responden sekitar 50 orang.

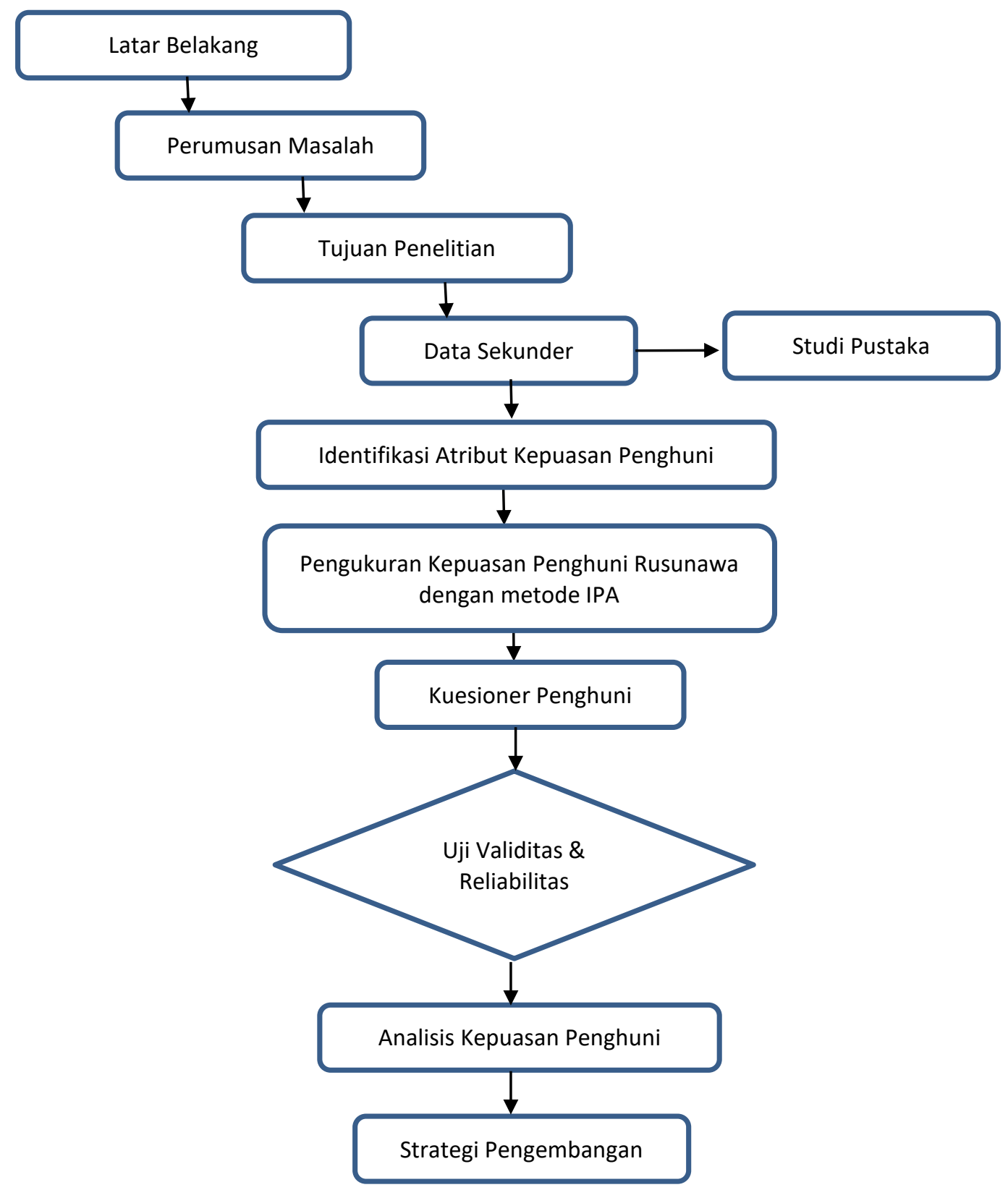

Gambar 1 Bagan Alur Pikir 


\section{PEMBAHASAN}

Rusunawa Semeru merupakan salah satu Rusunawa percontohan di Kota Probolinggo memiliki kondisi bangunan yang telah didesain dengan baik dan benar. Tampak depan kondisi rusun terlihat cukup baik karena hanya menampilkan nama rusun serta bangunan dan tidak ada kegiatan lain di area tampak depan, selain itu tampak depan terdapat taman yang menambah keindahan rusunawa. Namun terdapat permasalahan di tampak depan rusunawa, dikarenakan kurang adanya vegetasi sehingga menyebabkan kawasan rusunawa semeru terlihat tandus.

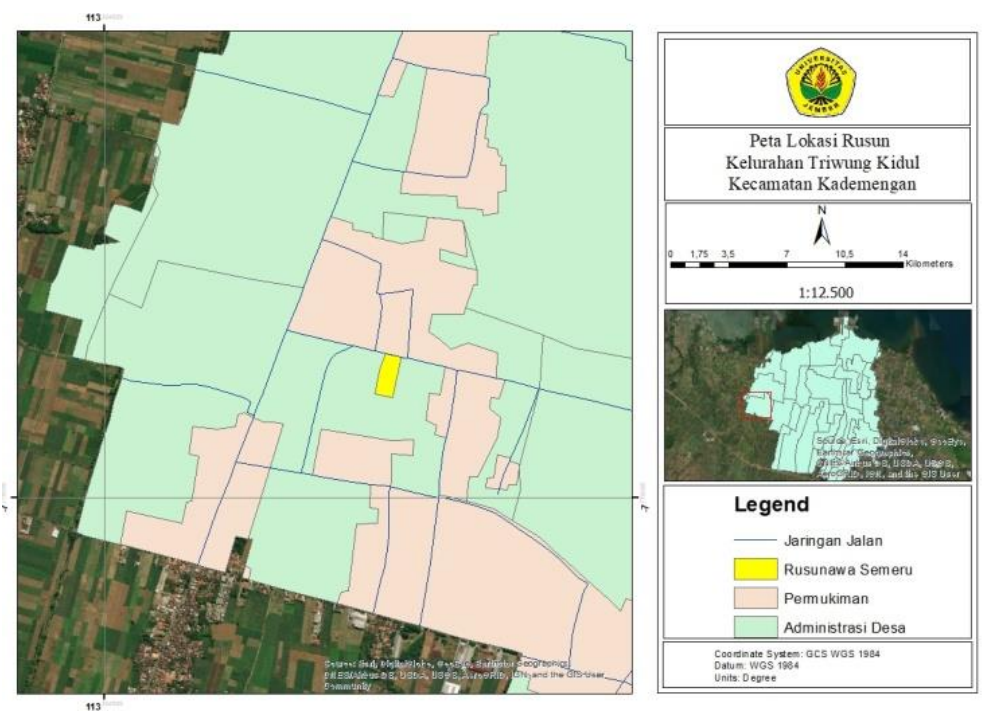

Gambar 1. Peta Lokasi Rusunawa Semeru Sumber : ArcGIS

Desain di dalam rusunawa semeru memiliki kondisi yang baik dengan jumlah lantai adalah 5 lantai dengan ketentuan lantai yang lebih tinggi (lantai 5) dihuni oleh penghuni yang berusia lebih muda. Selain itu, di dalam rusunawa telah dilengkapi dengan adanya pengaturan peletakkan kabel yang menyebabkan view terlihat indah, desain penyediaan tempat sampah di lantai atas yang bisa langsung ke lantai 1 juga memudahkan penghuni rusunawa di bagian atas. Di lantai 5 terdapat pencahayaan alami sehingga memudahkan dalam menjemur pakaian, di depan pintu masuk terdapat tangga bagi penghuni maupun mengunjung biasa dan terdapat pula jalur bagi penyandang disabilitas yang dapat memudahkan aksesibilitas keluar masuk rusunawa, parkiran sendiri terletak di lantai satu dan terdapat 2 titik lokasi yang disediakan sebagai parkiran. 

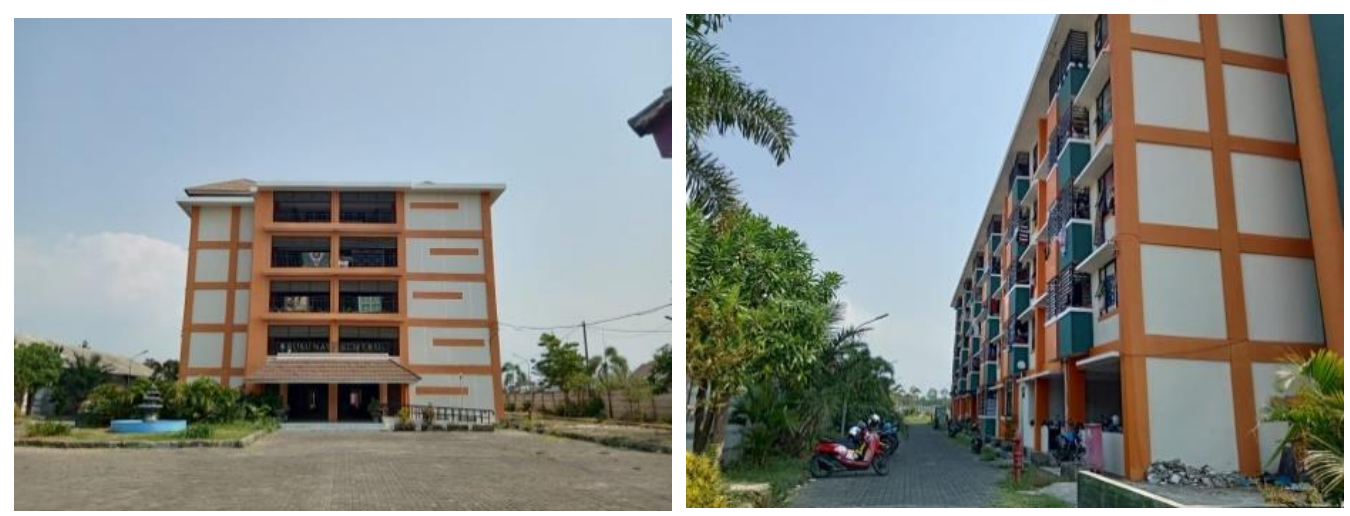

Gambar 3 Rusunawa Semeru Tampak Depan dan Samping Sumber : Survey Primer

Penghuni rusunawa semeru merupakan warga asli dari Kota Probolinggo yang rata-rata memiliki mata pencaharian sebagai wiraswasta dengan pendapatan kurang dari Rp. 1.500.000, 00 per bulan. Jumlah penduduk di Rusunawa Semeru terdiri dari 94 KK dimana $1 \mathrm{KK}$ diasumsikan terdiri dari 4 orang sehingga dapat diketahui bahwa jumlah penduduk di Rusunawa Semeru berjumlah 376 jiwa.

\section{- Hasil analisis IPA}

Untuk mengetahui kualitas layanan di Rusunawa Semeru serta memastikan usulan perbaikan tentang elemen/atribut pelayananan yang bermanfaat terhadap penghuni Rusunawa yang memiliki kinerja rendah, maka dilakukan langkah yaitu penempatan seluruh atribut pelayanan yang ada di kuadran-kuadran sesuai di matriks IPA. Sumbu didapatkan dari rata-rata nilai kepuasan pelanggan terhadap pelayanan dan sumbu y diperoleh dari rata-rata nilai kepentingan atribut pelayanan bagi pelanggan. Berikut merupakan bentuk diagram IPA yang dapat dilihat pada gambar 4 . 


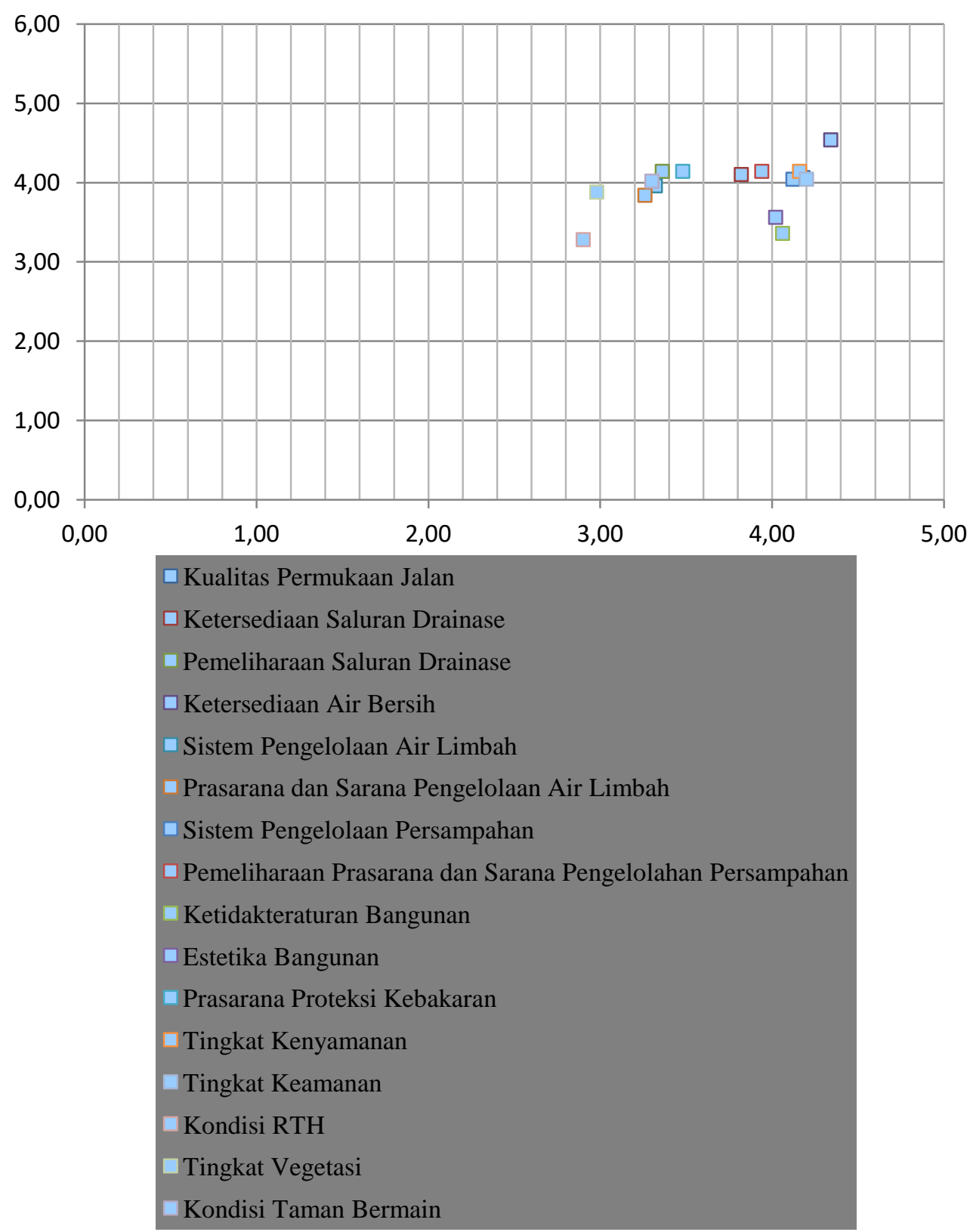

Gambar 4 Pemetaan Atribut Pada Diagram IPA

Sumber : Analisis 2019

Terdapat 7 atribut yang perlu mendapatkan prioritas berdasarkan pemeteaan di atas yaitu prasarana proteksi kebakaran, ketersediaan saluran drainase, pemeliharaan saluran drainase, sistem pengelolaan air limbah, sarana dan prasarana pengelolaan air limbah, tingkat vegetasi, dan kondisi taman bermain. Atribut-atribut yang terletak di kuadran I merupakan atribut-atribut yang penting, akan tetapi performanya masih rendah sehingga perlu dilakukan perbaikan sistem. Untuk kuadran II terdapat atribut-atribut yang memiliki kategori dipertahankan karena sudah sesuai dengan keinginan penghuni Rusunawa Semeru, berikut merupakan atribut yang terdapat di kuadran II :

1. Ketersediaan Air Bersih;

2. Tingkat Keamanan; 
3. Tingkat Kenyamanan;

4. Estetika Bangunan;

5. Pemeliharaan Prasarasan dan Sarana Pengelolaan Persampahan;

6. Kualitas Permukaan Jalan, dan;

7. Sistem Pengelolaan Persampahan.

Tabel 2. Rekap Penilaian Kuisioner Berdasarkan Nilai Kepuasan

\begin{tabular}{|c|c|c|c|}
\hline Aspek & Variabel & Nilai Kepuasan & $\begin{array}{c}\text { Nilai Rata-rata } \\
\text { Kepuasan }\end{array}$ \\
\hline Kondisi Jalan & Kualitas Permukaan Jalan & 209 & 4,18 \\
\hline \multirow[t]{2}{*}{ Kondisi Drainase } & Ketersediaan Saluran Drainase & 191 & 3,82 \\
\hline & Pemeliharaan Saluran Drainase & 168 & 3,36 \\
\hline $\begin{array}{l}\text { Penyediaan Air } \\
\text { Bersih } \\
\end{array}$ & Ketersediaan Air Bersih & 217 & 4,34 \\
\hline \multirow{2}{*}{$\begin{array}{l}\text { Pengelolaan Air } \\
\text { Limbah }\end{array}$} & Sistem Pengelolaan Air Limbah & 166 & 3,32 \\
\hline & $\begin{array}{c}\text { Prasarana dan Sarana Pengelolaan Air } \\
\text { Limbah }\end{array}$ & 163 & 3,26 \\
\hline \multirow{2}{*}{$\begin{array}{l}\text { Pengelolaan } \\
\text { Persampahan }\end{array}$} & Sistem Pengelolaan Persampahan & 206 & 4,12 \\
\hline & $\begin{array}{l}\text { Pemeliharaan Prasarana dan Sarana } \\
\text { Pengelolahan Persampahan }\end{array}$ & 197 & 3,94 \\
\hline \multirow[t]{2}{*}{ Kondisi Bangunan } & Ketidakteraturan Bangunan & 203 & 4,06 \\
\hline & Estetika Bangunan & 201 & 4,02 \\
\hline Bahaya Kebakaran & Prasarana Proteksi Kebakaran & 174 & 3,48 \\
\hline \multirow{2}{*}{$\begin{array}{l}\text { Keamanan dan } \\
\text { Kenyamanan }\end{array}$} & Tingkat Kenyamanan & 208 & 4,16 \\
\hline & Tingkat Keamanan & 210 & 4,20 \\
\hline \multirow[t]{3}{*}{ RTH } & Kondisi RTH & 145 & 2,90 \\
\hline & Tingkat Vegetasi & 149 & 2,98 \\
\hline & Kondisi Taman Bermain & 165 & 3,30 \\
\hline
\end{tabular}

Sumber : Analisis 2019

Tabel 3. Rekap Penilaian Kuisioner Berdasarkan Nilai Kepentingan

\begin{tabular}{|c|c|c|c|}
\hline \multicolumn{1}{|c|}{ Aspek } & \multicolumn{1}{c}{ Variabel } & Nilai Kepentingan & $\begin{array}{c}\text { Nilai Rata-rata } \\
\text { Kepentingan }\end{array}$ \\
\hline Kondisi Jalan & Kualitas Permukaan Jalan & 203 & 4,06 \\
\hline Kondisi Drainase & Ketersediaan Saluran Drainase & 205 & 4,10 \\
\hline & Pemeliharaan Saluran Drainase & 207 & 4,14 \\
\hline $\begin{array}{r}\text { Penyediaan Air } \\
\text { Bersih }\end{array}$ & Ketersediaan Air Bersih & 227 & 4,54 \\
\hline Pengelolaan Air & Sistem Pengelolaan Air Limbah & 198 & 3,96 \\
\hline
\end{tabular}




\begin{tabular}{|r|c|c|c|}
\hline \multicolumn{1}{|c|}{$\begin{array}{c}\text { Prasarana dan Sarana Pengelolaan Air } \\
\text { Limbah }\end{array}$} & 192 & 3,84 \\
\hline $\begin{array}{c}\text { Pengelolaan } \\
\text { Persampahan }\end{array}$ & $\begin{array}{c}\text { Sistem Pengelolaan Persampahan } \\
\text { Pemeliharaan Prasarana dan Sarana } \\
\text { Pengelolahan Persampahan }\end{array}$ & 207 & 4,04 \\
\hline Kondisi Bangunan & Ketidakteraturan Bangunan & 168 & 3,36 \\
\hline Bahaya Kebakaran & Prasarana Proteksi Kebakaran & 178 & 3,56 \\
\hline Keamanan dan & Tingkat Kenyamanan & 207 & 4,14 \\
\hline Kenyamanan & Tingkat Keamanan & 207 & 4,14 \\
\hline RTH & Kondisi RTH & 202 & 4,04 \\
\hline & Tingkat Vegetasi & 164 & 3,28 \\
\hline
\end{tabular}

Sumber : Analisis 2019

Selanjutnya merupakan atribut yang terletak di kuadran III yaitu atribut yang termasuk ke dalam kategori prioritas rendah dimana tingkat kepentingan relatif rendah dan kondisi lapangan tidak sesuai dengan tingkat kepuasan. Contohnya yaitu kondisi RTH (Ruang Terbuka Hijau). Atribut yang terletak di kuadran IV merupakan kategori yang memiliki kondisi cukup baik dengan tingkat kepentingan yang relatif rendah yaitu ketidakteraturan bangunan.

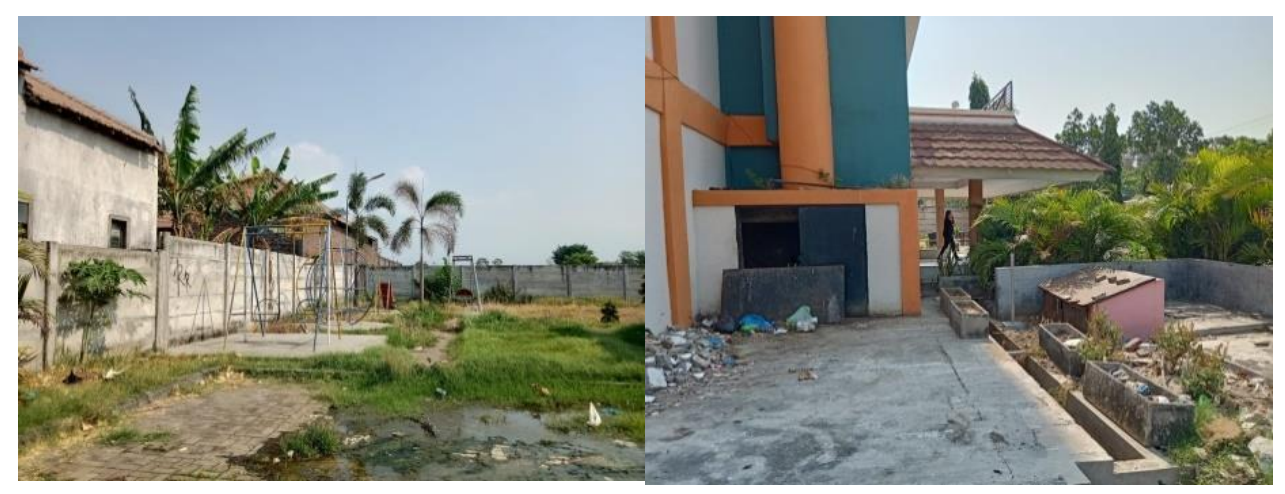

Gambar 5. Kondisi RTH di Rusunawa Semeru Sumber : Survey Primer

\section{- Uji Validitas dan Reliabilitas}

Uji validitas digunakan sebagai alat pengukur ketepatan kuisioner terhadap variable-variabel pertanyaannya. Pada uji validitas ini, akan digunakan nilai koefisien pearson. Suatu item pertanyaan pada kuisioner dinyatakan valid apabila nilai r-hitung lebih besar dari nilai r-tabel. (r-hitung $>$ r-tabel).

Nilai r-tabel dalam penelitian ini diketahui sebesar 0,2787 yang diperoleh dari table dengan degree of freedom (df) sebesar 48 dari jumlah 50 kuisioner yang disebarkan ke responden sebagai uji coba dengan taraf kepercayaan (sig 50\%). Dari perhitungan secara keseluruhan, semua item pertanyaan dinyatakan valid karena nilai $r$-hitung $>r-$ 
tabel yaitu 1,00>0,279 sehingga keseluruhan item pertanyaan pada kuisioner dapat digunakan untuk mengukur kualitas pelayanan rusunawa semeru dan melanjutkan penyebaran kuisioner kepada responden.

Setelah mengetahui validitas kuisioner, kemudian dilihat tingkat reliabilitas variable yang digunakan. Uji reliabilitas digunakan sebagai alat pengukur kepercayaan kuisioner yang telah disebarkan karena kuisioner tersebut harus memiliki hasil pengukuran yang relative konsisten dari waktu ke waktu sehingga dapat digunakan kembali ketika dibutuhkan. Teknik yang digunakan untuk menguji reliabilitas kuisioner adalah teknik reliabilitas koefisien Cronbach's alpha $(\alpha)$. Kuisioner dinyatakan reliable apabila nilai $\alpha>0,60$.

Tabel 4. Cronbach's Alpha Variabel X

\begin{tabular}{|c|l|l|l|}
\hline $\begin{array}{l}\text { Jumlah Item } \\
\text { Pertanyaan }\end{array}$ & $\begin{array}{l}\text { Koefisien Crobach's } \\
\text { Alpha hitung pada } \\
\text { tingkat kepuasan }\end{array}$ & $\begin{array}{l}\text { Koefisien Crobach's } \\
\text { Alpha hitung pada } \\
\text { tingkat kepentingan }\end{array}$ & $\begin{array}{l}\text { Koefisien } \\
\text { Crobach's Alpha } \\
\text { standar }\end{array}$ \\
\hline 16 & 1,00 & 1,00 & 0,60 \\
\hline
\end{tabular}

Untuk mengukur kemantapan alpha pada uji reliabilitas ini yaitu dengan menginterpretasikan nilai alpha yang telah dihitung kedalam 5 kelas kriteria reliabilitas pada table dibawah ini (Budi, 2006)

Tabel 5. Kriteria Reliabilitas

\begin{tabular}{|l|l|}
\hline Crobach's Alpha & Tingkat Reliabilitas \\
\hline 0,00 s.d 0,20 & Kurang Reliable \\
\hline$>0,20$ s.d 0,40 & Agak Reliable \\
\hline$>0,40$ s.d 0,60 & Cukup Reliable \\
\hline$>0,60$ s.d 0,80 & Reliable \\
\hline$>0,80$ s.d 1,00 & Sangat Reliable \\
\hline \multicolumn{2}{|c|}{ Sumber : Hasil Analisis Data SPSS, 2019 } \\
\hline
\end{tabular}

Interpretasi dari hasil uji reliabilitas pada table diatas yaitu bahwa kuesioner yang telah disebar dinyatakan reliabel karena memiliki nilai $\alpha=1,00$ pada masing-masing tingkatan yang berarti nilai $\alpha>0,60$ sehingga kuesioner dapat disebar kembali kepada responden.

\section{- Strategi Pengembangan}

Berdasarkan hasil analisis Tingkat Kepuasan masyarakat terhadap pelayanan Rusunawa Semeru, dapat dihasilkan strategi guna peningkatan kualitas pelayanan sarana dan prasarana di Rusunawa Semeru. Strategi peningkatan kualitas pelayanan rusunawa semeru adalah sebagai berikut:

a. Penambahan prasarana proteksi kebakaran, untuk mengantisipasi terjadinya kebakaran.

b. Peningkatan kualitas saluran drainase melalui pembersihan dan pemeliharaan rutin yang dilakukan oleh penghuni Rusunawa Semeru.

c. Pemeliharaan sarana dan prasarana terkait pengelolaan air limbah

d. Peningkatan sistem pengelolaan air limbah dengan baik dan benar 
e. Penambahan vegetasi atau tanaman hijau untuk menambah keindahan dan mengurangi tingkat polusi

f. Perbaikan kondisi taman bermain dan pemeliharaan serta perawatannya yang baik dari penghuni Rusunawa Semeru.

g. Pemerintah dapat memberikan penanganan efektif terhadap keluhan penghuni Rusunawa Semeru terkait dengan perbaikan sarana dan prasarana.

h. Pengadaan sosialisasi kepada penghuni Rusunawa Semeru untuk selalu menjaga kebersihan dan pemeliharaan terhadap fasilitas dan utilitas yang ada

Dengan adanya strategi peningkatan kualitas pelayanan ini diharapkan dapat terealiasasikan dengan baik guna menunjang keberlangsungan hidup masyarakat Rusunawa Semeru Probolinggo.

\section{KESIMPULAN}

Berdasarkan hasil penelitian diatas mengenai kualitas pelayanan Rusunawa Semeru Probolinggo dapat disimpulkan sebagai berikut :

- Pengadaan sarana dan prasarana pelayanan Rusunawa Probolinggo sudah mencapai kriteria yang telah ditetapkan, akan tetapi dalam pemeliharaannya masih sangat kurang karena ada beberapa sarana dan prasarana yang masih terbengkalai dan kurang perawatan seperti Ruang Terbuka Hijau dan Taman Bermain, Saluran Drainase, Tempat Pembuangan Sampah dan Pengelolaan Limbah.

- Ketersediaan Air Bersih; Tingkat Keamanan; Tingkat Kenyamanan; Estetika Bangunan; Pemeliharaan Prasarasan dan Sarana Pengelolaan Persampahan; Kualitas Permukaan Jalan, dan; Sistem Pengelolaan Persampahan sudah dinilai baik oleh penghuni rusunawa Semeru. Namun untuk prasarana proteksi kebakaran, ketersediaan saluran drainase, pemeliharaan saluran drainase, sarana dan prasarana pengelolaan air limbah, sistem pengelolaan air limbah, tingkat vegetasi, dan kondisi taman bermain masih kurang, sehingga perlu adanya penambahan dan perbaikan sarana dan prasarana di Rusunawa Semeru.

- Strategi Pengembangan Rusunawa Semeru lebih difokuskan pada prasarana proteksi kebakaran, saluran drainase, saluran drainase, IPAL, RTH, dan taman bermain. Strategi pengembangan tersebut berupa konsep desain perencanaan rusunawa disesuaikan dengan kondisi eksisting dan hasil analisis IPA.

\section{DAFTAR PUSTAKA}

Budi, Triton P. 2006. SPSS 13.0 Terapan, Riset Statistik Parametrik. Yogyakarta : Penerbit Andi Publisher

Hidayati, Masturina Kusuma. 2017. Tingkat Kepuasan Penghuni Rusunawa Terhadap Fisik Lingkungan Rusunawa di Surakarta. Universitas Gadjah Mada (UGM)

Irfiyanti, Zulinar dan Widjonarko. 2014. Penyediaan Rumah Susun Sederhana Sewa Ditinjau dari Preferensi Masyarakat Berpenghasilan Rendah di Kabupaten Kudus. Jurnal Teknik PWK. Vol. 3 no.4 2014

Koesoemawati. D.J, H. Yuswadi, A. Ratnaningsih, R. Alfiah, M. Firmansyah. 2019. Neighbourhood space for formal housing based on social cohesion inJember Region. IOP Conference Series: Earth and Environmental Science. Vol. 340, No. 1 
Koesoemawati. D.J, H. Yuswadi. 2017. Model Neighborhood pada Ruang Publik Perkotaan Ditinjau dari Perilaku dan Aktivitas di Melting Pot Kota Jember. Seminar Nasional Planoearth\#1 2017. Vol. 1, ISBN. 978-602-50730-0-7:363369

Pandelaki, Edward Endrianto, Edi Purwanto, Deasy Olivia, dan Wisnu Agung. 2015. Faktor - Faktor Pembentuk Kinerja Spasial Rumah Susun Kaitannya dengan Kepuasan Penghuni. Semarang : Fakultas Teknik Universitas Diponegoro

Putri, Mangesti Carissa, Dewi Junita Koesoemawati, dan Ani Trisiana. 2019. Analisis Kepuasan Pelanggan Terhadap Sarana Prasarana dan Lokasi Perumahan Menggunakan Metode Quality Function Deployment (Studi Kasus Perumahan Griya Pesona Karangrejo Banyuwangi. Berkala Sainstek. VII (2): 53-58.

Undang-Undang Nomor 1 Tahun 2011 Tentang Perumahan dan Kawasan Permukiman Undang-Undang Republik Indonesia Nomor 20 Tahun 2011 Tentang Rumah Susun 